\title{
Assessment of the Quality of Soil and Groundwater of the Agricultural Area of Sidi Yahya Region, Morocco
}

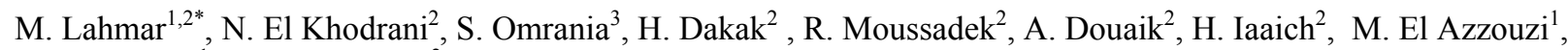 \\ M. Mekkaoui ${ }^{1}$, and A. Zouahri ${ }^{2}$ \\ ${ }^{1}$ Laboratory of Materials, Nanomaterials and Environment Physicochemistry Team, Faculty of Sciences, Mohammed V \\ University, Rabat, Morocco. \\ ${ }^{2}$ Research Unit on Environment and Conservation of Natural Resources, Regional Center of Rabat, \\ National Institute of Agricultural Research (INRA), Rabat ,Morocco.
}

${ }^{3}$ Laboratory of Spectroscopy, Molecular Modeling, Materials, Nanomaterials, Waters and Environment, CERNE2D, Faculty of Sciences, Mohammed V University, Rabat, Morocco.

\begin{abstract}
The Gharb plain is the largest agricultural area in Morocco. It is characterized by fertile soils and the availability of water either from surface or groundwater which allowed intensive agriculture. The aim of this research work is to study the impact of this land management on the quality of water and soil. The study was done for the irrigated perimeter of Sidi Yahya belonging to the province of Sidi Slimane, Gharb (Morocco). Depth of water table and water pH were measured in situ while water and soil samples were collected and brought to the laboratory for their physico-chemical analyses. Sampling of 33water wells and soil samples, from six different zones, was done between May and October 2018.Analysis of variance (ANOVA) was used to check if mean water and soil parameters differed between zones. The results showed that the minimal and maximal water table depth were 6 and $96 \mathrm{~m}$, respectively. Also, slightly more than half of the wells $(51.5 \%)$ were inadequate for irrigation since they were either highly or extremely saline. Furthermore, soils were poor to moderately poor in organic matter but very rich in potassium and the phosphorus content was highly variable. Based on the statistical analysis, it is clear that the six zones had significantly different means for $\mathrm{CaCO}_{3}, \mathrm{pH}, \mathrm{OM}$, and exchangeable sodium percentage. Soil degradation like pollution and salinization may occur in this region if poor quality water is used for irrigation and if land is mismanaged. This research work can be considered as a first step towards a program for monitoring the quality of soil and water for adapting the land management with the final objective of securing high productivity and sustainable use of soil and water resources.
\end{abstract}

\section{Introduction}

Soil and water are two vital and essential resources for life on the earth. In Morocco, soils and waters are more and more degraded and this degradation is going stronger and speedy [1]. Water quality is becoming polluted leading to the decrease of the potential of the water resources and impacting health risk for rural population [2-3]. Many research studies regarding soil and water quality were done in different regions of Morocco, mainly in irrigated districts [2,4-6]. Also, many other studies have been done all around the world and showed that degradation of soil and groundwater quality is an international environmental issue that can be a major threat to agriculture since it limits crop production and compromises the sustainability of the different agroecosystems [7].Most of the degradation factors of soil and water quality are anthropogenic, mainly related to inappropriate crop practices like mismanagement of irrigation water and agro-chemical inputs. For example, salinization and sodification of agricultural lands, due to the use of irrigation with marginal and poor-quality water (mainly groundwater), are increasing rapidly [8]. Therefore, around $30 \%$ of world irrigated surface is saline. The Mediterranean region registers approximately 16 million hectares [2].

The Sidi Yahya region in the Gharb plain (Morocco) is well known for its intensive agriculture since it has fertile soils and available water. However, the quality of these soils and waters should be assessed after a long-term use of these resources. Therefore, the main aim of this research work is to evaluate some physical and chemical parameters of soil and water and measure how they were affected by the intensive agricultural activities in the region.

*Corresponding author: 1ahmar.mbark@gmail.com 


\section{Materials and methods}

\subsection{Study area}

The city of Sidi Yahya is a municipality within the province of Sidi Slimane belonging to the region of Rabat-Sale-Kenitra. It is located about $26 \mathrm{~km}$ North East of the city of Kenitra. The study area is located at the South East of the Gharb plain, on the transition zone between the Maâmora and the Gharb water tables. The Gharb plain has a very low altitude but large basin that covers an area of $616000 \mathrm{ha}$ [9]. The geographic coordinates of the study area are $34^{\circ} 18^{\prime} 33^{\prime \prime} \mathrm{N}$ for latitude and $6^{\circ} 18^{\prime} 41^{\prime \prime}$ $\mathrm{W}$ for longitude. The climate of the region is largely influenced by the Atlantic oceanic, within a sub-humid bioclimatic zone with a moderate temperature and high air humidity in winter and high temperature in the summer.

\subsection{Sampling and laboratory analyses}

Thirty three soil and water samples were collected, in May and October 2018, from six zones for the whole Sidi Yahya region, Gharb plain (Figure1). The sampling was based on a well developed mesh size using a topographic map of the study area. The samples were conditioned and transported in a cooler at $4^{\circ} \mathrm{C}$ for laboratory analysis in the Research Unit on the Environment and Conservation of Natural Resources, National Institute of Agricultural Research in Rabat.

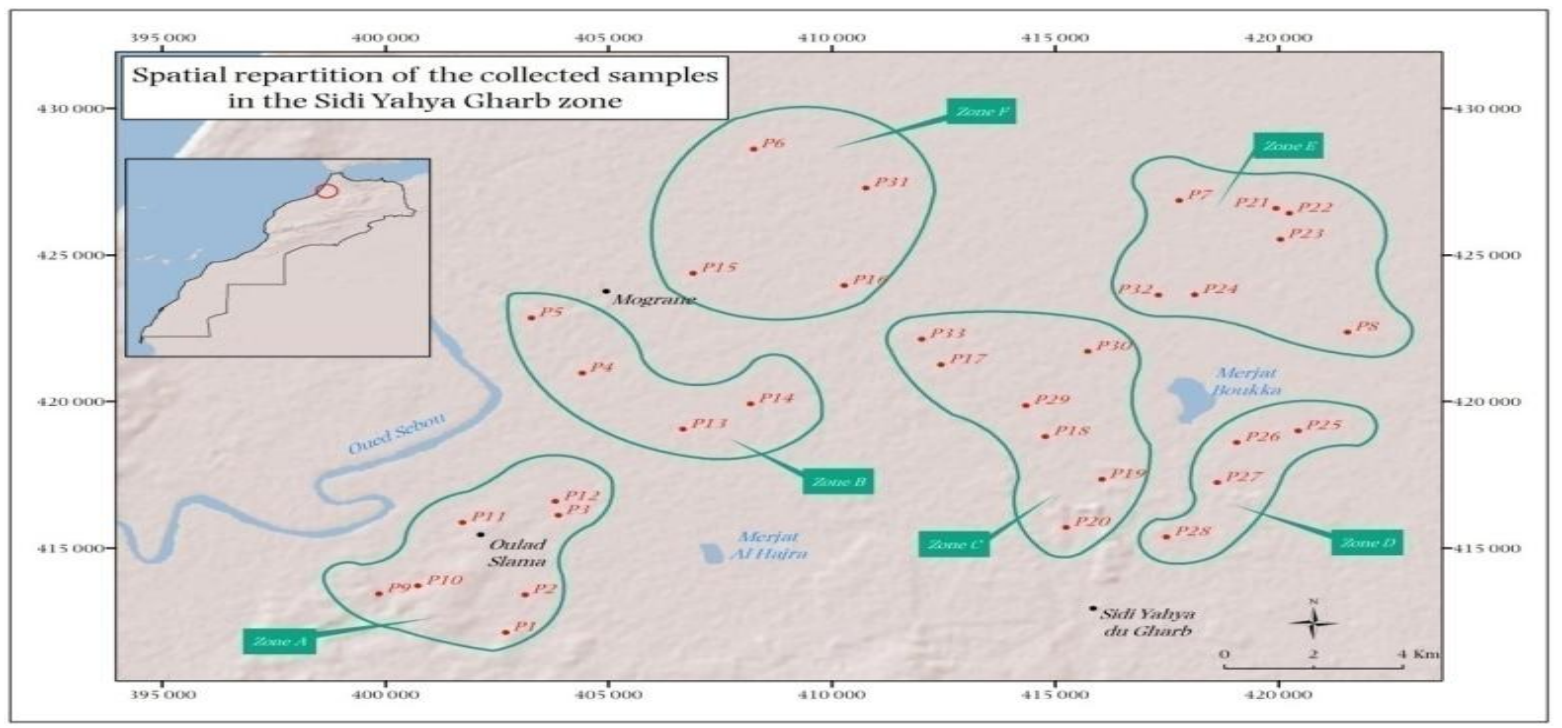

Fig. 1.Study area with the 6 zones and soil and water samples.

\subsubsection{Soil analyses}

Soil samples were taken at the $0-20 \mathrm{~cm}$ depth using an auger. They were air-dried, crushed, sieved, and registered for laboratory analysis. Several physical and chemical quality parameters were measured like $\mathrm{pH}$, electrical conductivity, organic matter, available phosphorus, exchangeable potassium, and soil texture. They were analyzed following international standards:

- pH (Hydrogen potential)was determined using the potentiometric method using a Mettler Toledo Seven Easy-728 Metrohm pHmeter)[10].

- Electrical conductivity (EC), in $\mathrm{dS} / \mathrm{m}$, was measured on a 1:5 soil: water paste using an ORION conductivity meter, model 162 [11].

- Organic matter (OM), in \%, was evaluated using the Walkely and Black method which is based on the oxidation of organic carbon by potassium dichromate $\left(\mathrm{K}_{2} \mathrm{Cr}_{2} \mathrm{O}_{7}\right.$ to $\left.1 \mathrm{~N}\right)$ [12].

- Available phosphorus (P2O5), in ppm, was determined using the Olsen method where the extraction is made by sodium hydrogencarbonate at $\mathrm{pH} 8.5$ [13].This method is based on the formation and reduction of a complex of the orthophosphoric acid and molybdic acid (sky blue). The phosphorus content is read using a JENWAY 6405 Visiblemodel UV spectrophotometer at a wavelength of $825 \mathrm{~nm}$.

- Exchangeable potassium and sodium, in ppm, were measured by the extraction using the ammonium acetate $\mathrm{CH}_{3} \mathrm{COONH}_{4} 1 \mathrm{~N}$ at $\mathrm{pH} 7$ [10]. The $\mathrm{K}_{2} \mathrm{O}$ and $\mathrm{Na}^{+}$levels were determined using a flame photometer model CL 378. 
- Soil texture was determined by measuring soil particle sizes using sedimentation. The purpose of the manipulation is to determine the texture of the soil by classifying the mineral constituents according to the diameter of their elementary particles: clay $(<2 \mu \mathrm{m})$, fine silt $(2-$ $20 \mu \mathrm{m})$, coarse silt $(20-50 \mu \mathrm{m})$, fine sand $(50-$ $200 \mu \mathrm{m})$, and coarse sand $(>200 \mu \mathrm{m})$ by sedimentation according to the Stokes law [14].

\subsubsection{Water analyses}

Water samples were taken from we0lls that were located, as much as possible, near to soil samples. Some water quality parameters like groundwater depth and $\mathrm{pH}$ were measured in situ. The water samples were placed in sealed plastic bottles with the site code (Wx), with $\mathrm{W}$ referring to the well and $\mathrm{x}$ the site number and stored in a cooler $\left(2\right.$ to $\left.4^{\circ} \mathrm{C}\right)$. Maximum 72 hours, then sent to the laboratory for physico-chemical analyzes.
One factor analysis of variance (ANOVA) was used to compare the mean values of soil and water parameters for the six zones to check whether they differed significantly or not [15]. Whenever ANOVA showed statistically significant differences between zones, the Duncan posthoc test was used to identify homogeneous groups of zones [16].

\section{Results and discussion}

\subsection{Soil quality}

Means, their corresponding standard deviations, and ANOVA results for soil quality parameters are given in table 1.There were no significant differences between the six zones regarding EC, $\mathrm{P}_{2} \mathrm{O}_{5}$, and $\mathrm{K}_{2} \mathrm{O}$; these parameters will no longer be discussed whereas parameters for which significant differences were found will be presented in detail below.

\subsection{Statistical analyses}

Table 1.Means \pm standard deviations and ANOVA results for soil physical and chemical parameters for the 6 zones.

\begin{tabular}{|c|c|c|c|c|c|c|c|c|}
\hline \multirow{2}{*}{ Parameters } & \multicolumn{6}{|c|}{ Zones } & \multicolumn{2}{|c|}{ Signification } \\
\hline & $\mathbf{A}$ & B & $\mathbf{C}$ & D & $\mathbf{E}$ & $\mathbf{F}$ & F-value & p-value \\
\hline $\mathrm{CaCO}_{3}(\%)$ & $2.8 \pm 3.9$ & $7.3 \pm 6.1$ & $1.1 \pm 1.4$ & $1.3 \pm 1.6$ & $12.2 \pm 4.9$ & $10.2 \pm 5.5$ & 7.95 & 0 \\
\hline pH & $7.8 \pm 0.3$ & $8.3 \pm 0.3$ & $8.0 \pm 0.4$ & $6.9 \pm 0.8$ & $8.3 \pm 0.1$ & $8.1 \pm 0.2$ & 7.75 & 0 \\
\hline$E C(d S / m)$ & $1.1 \pm 1.513$ & $1.178 \pm 2.7$ & $0.9 \pm 0.7$ & $1.2 \pm 1.3$ & $1.2 \pm 0.9$ & $0.7 \pm 0.2$ & 0.32 & 0.90 \\
\hline OM(\%) & $1.8 \pm 1.0$ & $3.1 \pm 1.0$ & $3.0 \pm 1.0$ & $2.3 \pm 0.8$ & $2.8 \pm 0.7$ & $4.0 \pm 0.8$ & 3.59 & 0.01 \\
\hline $\mathrm{P}_{2} \mathrm{O}_{5}(\mathrm{ppm})$ & $59.3 \pm 30.7$ & $19.6 \pm 16.9$ & $70.3 \pm 60.0$ & $29.9 \pm 29.6$ & $28.1 \pm 51.1$ & $32.8 \pm 22.0$ & 1.34 & 0.28 \\
\hline $\mathrm{K}_{2} \mathrm{O}(\mathrm{ppm})$ & $211.3 \pm 172.4$ & $360.8 \pm 17.8$ & $345.0 \pm 139.3$ & $330.7 \pm 390.8$ & $351.7 \pm 133.0$ & $576.2 \pm 305.3$ & 1.61 & 0.19 \\
\hline EPS (\%) & $24.9 \pm 21.7$ & $58.3 \pm 11.3$ & $46.0 \pm 23.4$ & $42.2 \pm 13.0$ & $74.2 \pm 12.9$ & $70.0 \pm 16.9$ & 6.50 & 0 \\
\hline
\end{tabular}

\subsubsection{Total limestone}

Limestone can have harmful or beneficial effects on plants, depending on the natural environment. Some plants grow in lime-free environments, while others thrive naturally in lime-rich environments. The higher the total $\mathrm{CaCO}_{3}$ level in the soil, the greater the risk of immobilization of trace element and phosphorus.
The ANOVA result showed that there was very highly significant difference between the six zones regarding their mean limestone contents $(\mathrm{F}$-value $=$ 7.95 and $p$-value $=0$ ). In fact, and based on the Duncan test, soils in zones $\mathrm{B}, \mathrm{F}$, and $\mathrm{E}$ are moderately calcareous with $7.3,10.2$, and $12.29 \%$, respectively whereas those in zones $\mathrm{C}, \mathrm{D}$, and $\mathrm{A}$ are less calcareous $(1.1,1.3$, and $2.8 \%$, respectively) (Table 1 and Figure 2). 


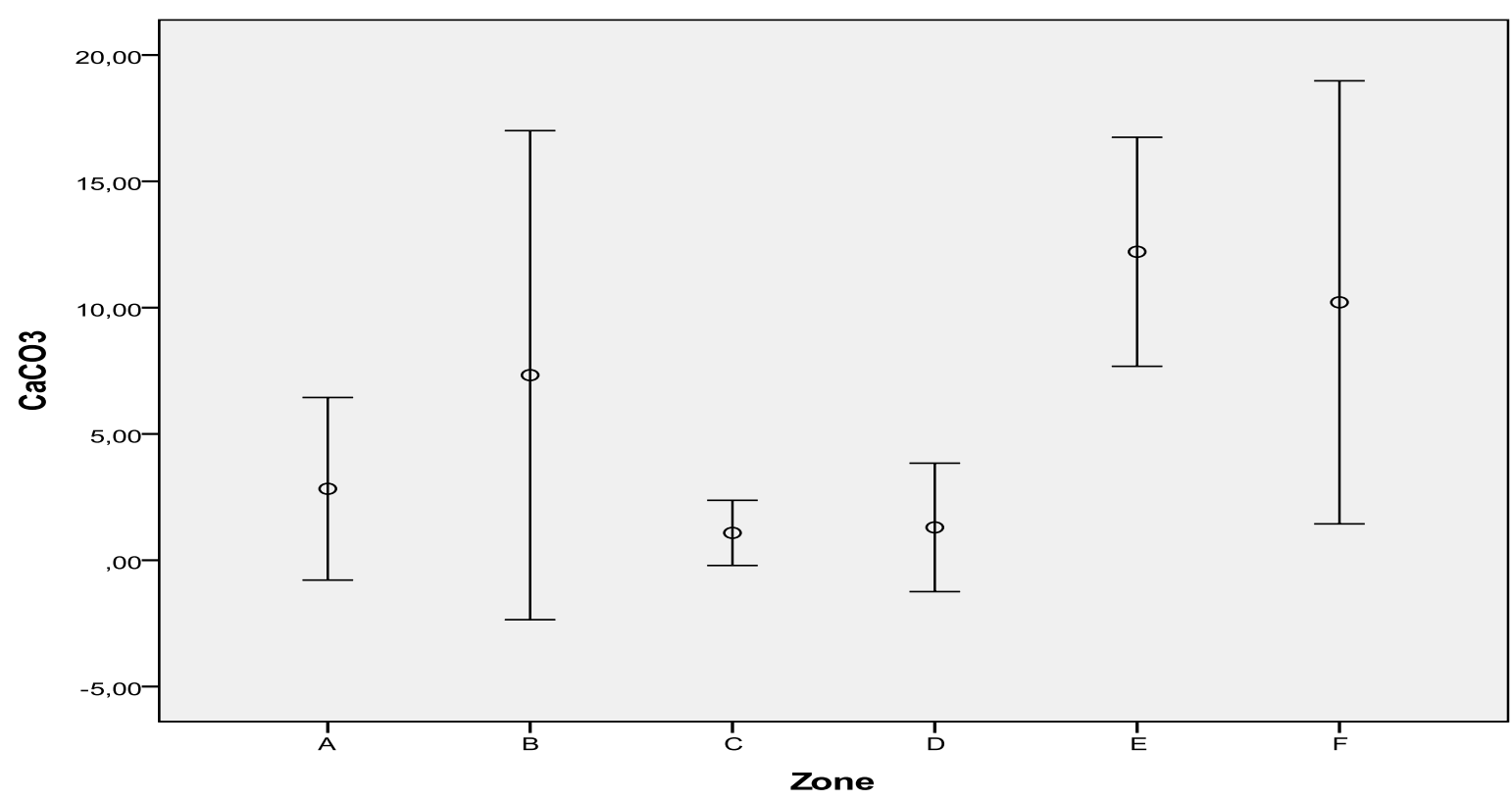

Fig. 2. $\mathrm{CaCO}_{3}$ mean values and their standard deviations for the 6 zones.

\subsubsection{Potential hydrogen}

Soil $\mathrm{pH}$ is a key variable in soils since it controls several chemical and biochemical processes that occur in soil. It is a measure of the acidity or alkalinity of a soil. It is very important to assess soil $\mathrm{pH}$ because it regulates the availability of plant nutrients by controlling the chemical forms of the various nutrients and also influences their chemical reactions. Therefore, the productivity of the soil and the crops is intimately linked to the $\mathrm{pH}$ value of the soil [17-18].

Following the ANOVA results (Table 1 and Figure 3 ), mean $\mathrm{pH}$ values differed significantly between the six zones $(F$-value $=7.75$ and $p$-value $=0)$. The Duncan test indicated the presence of two distinct groups of zones: zone $\mathrm{D}$ alone with a mean $\mathrm{pH}$ value of 6.9 whereas all the remaining zones are together forming a homogeneous group with mean $\mathrm{pH}$ values ranging from 7.8 (zone A) to 8.3 (zone B).

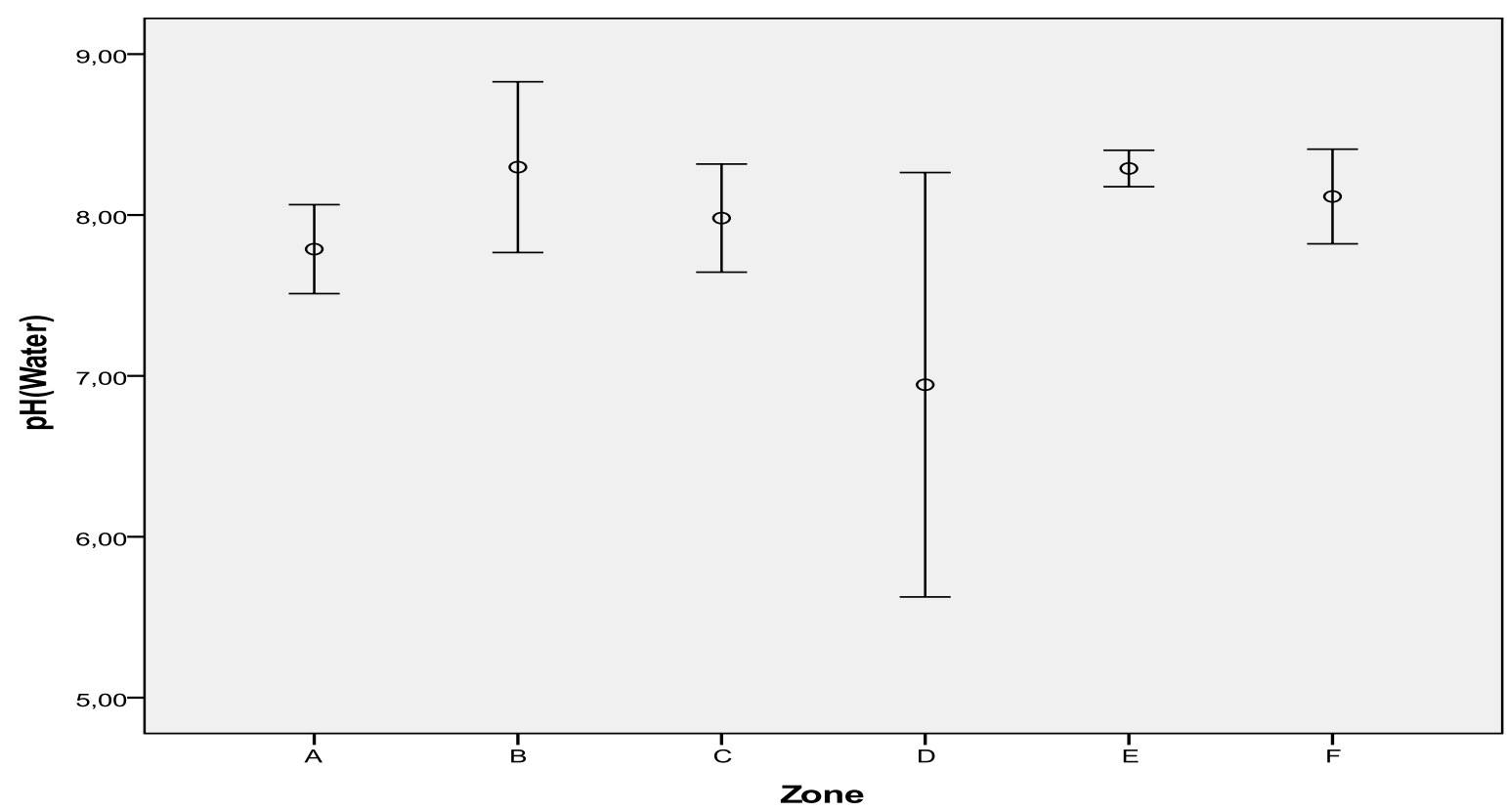

Fig. 3. pHmean values and their standard deviations for the 6 zones.

\subsubsection{Organic matter}

Soil organic matter can be considered as one of the most important indicators of soil quality [19] as it contribute to soil stability, increase in soil waterholding capacity, fixing of mineral elements, and constitutes a substrate for 
soil microorganisms. Soil organic matter content is influenced by many factors like climate, vegetation, soil texture, topography, irrigation and drainage, cropping practices, etc. [20].

From the ANOVA results (Table 1), it is clear that the six zones have significantly different levels of $\mathrm{OM}(\mathrm{F}$-value $=3.59$ and $\mathrm{p}$-value $=0.01)$. Zone $\mathrm{F}$ has, by far, the richest soils regarding OM (Figure 4) with a mean value of $4.0 \pm 0.8 \%$, followed by zones B, C, and $\mathrm{E}$ with $3.1 \pm 1.0,3.0 \pm 1.1$, and $2.8 \pm 0.7 \%$, respectively.

The Duncan test showed that three groups of zones can be identified based on the mean OM content:

-The first group contains zones A, D, and E with the lowest contents (1.8 to $2.8 \%$ ).

-The second group includes only zone $\mathrm{F}$ with the highest content $(4.0 \%)$.

- The third group includes zones B and C with intermediate contents (3.0 and 3.1\%).

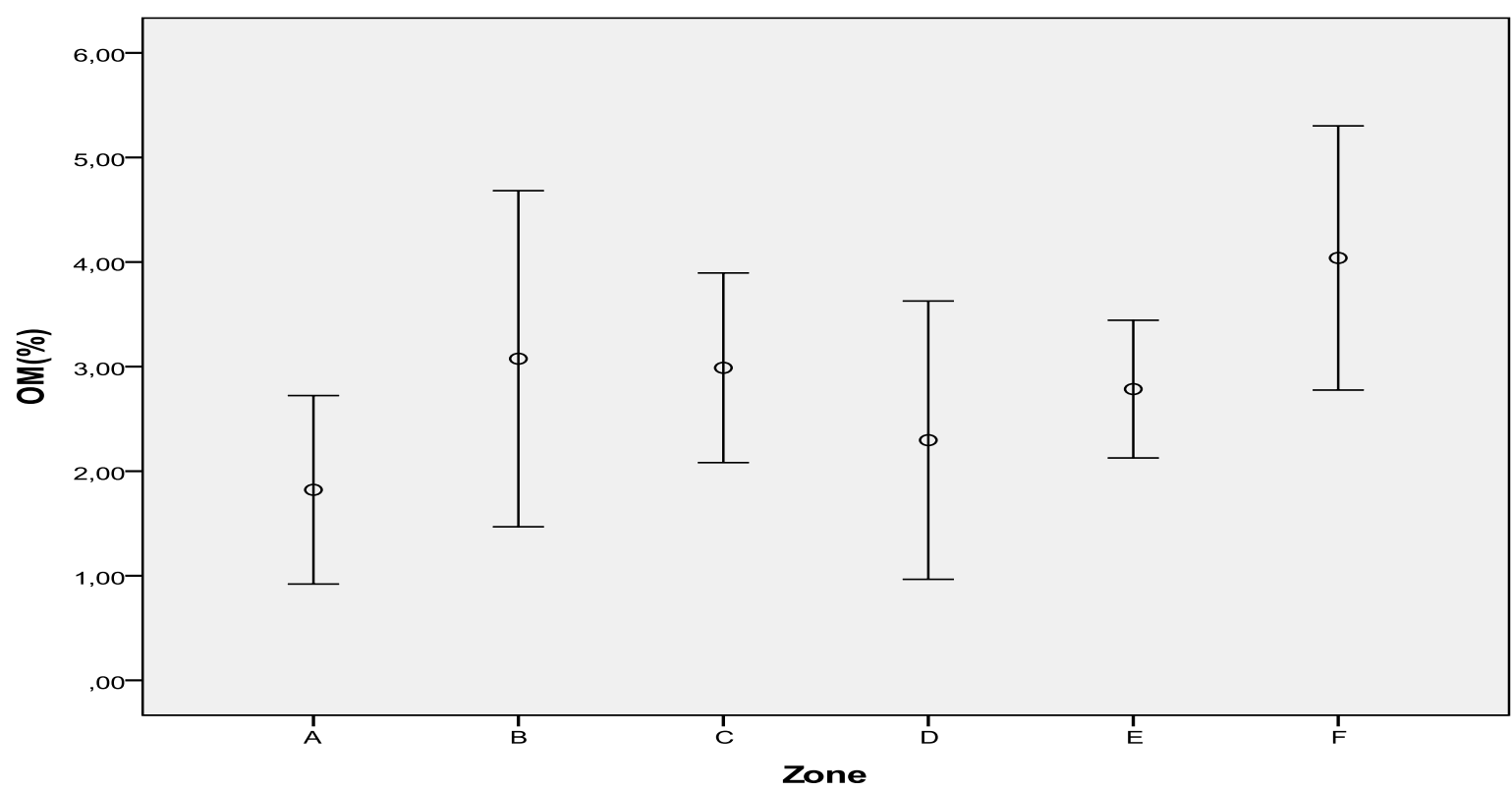

Fig. 4. OM mean values and their standard deviations for the 6 zones.

\subsubsection{Alkalinity}

Soil alkalinity is the result of the accumulation of soluble salts in the soil, especially $\mathrm{Na}$ [21]. Soil alkalinity is measured using exchangeable sodium percentage (ESP). According to Badraoui and Merzouk (1994) [22], when ESP exceeds 10\%, the soil becomes sodic, and the excess of exchangeable sodium leads to the deterioration of the soil structure by a dispersing effect on the colloids of the soil leading to a decrease in aeration and infiltration rate. Sodicity can originate either from intake of sodium from irrigation water (high sodium adsorption ratio, SAR) or from capillary upwelling of groundwater loaded with $\mathrm{Na}$.

The six zones were significantly different regarding ESP $(F$-value $=6.50$ and $p$-value $=0)($ Table 1$)$. In fact, $12.1 \%$ of soil samples are not alkaline and belong to zone A, only $6 \%$ can be considered slightly or moderately alkaline and are coming from zones B, C, and D whereas $63.7 \%$ of soil samples are highly alkaline and are located in zones $\mathrm{E}$ and $\mathrm{F}$ (Figure 5). 


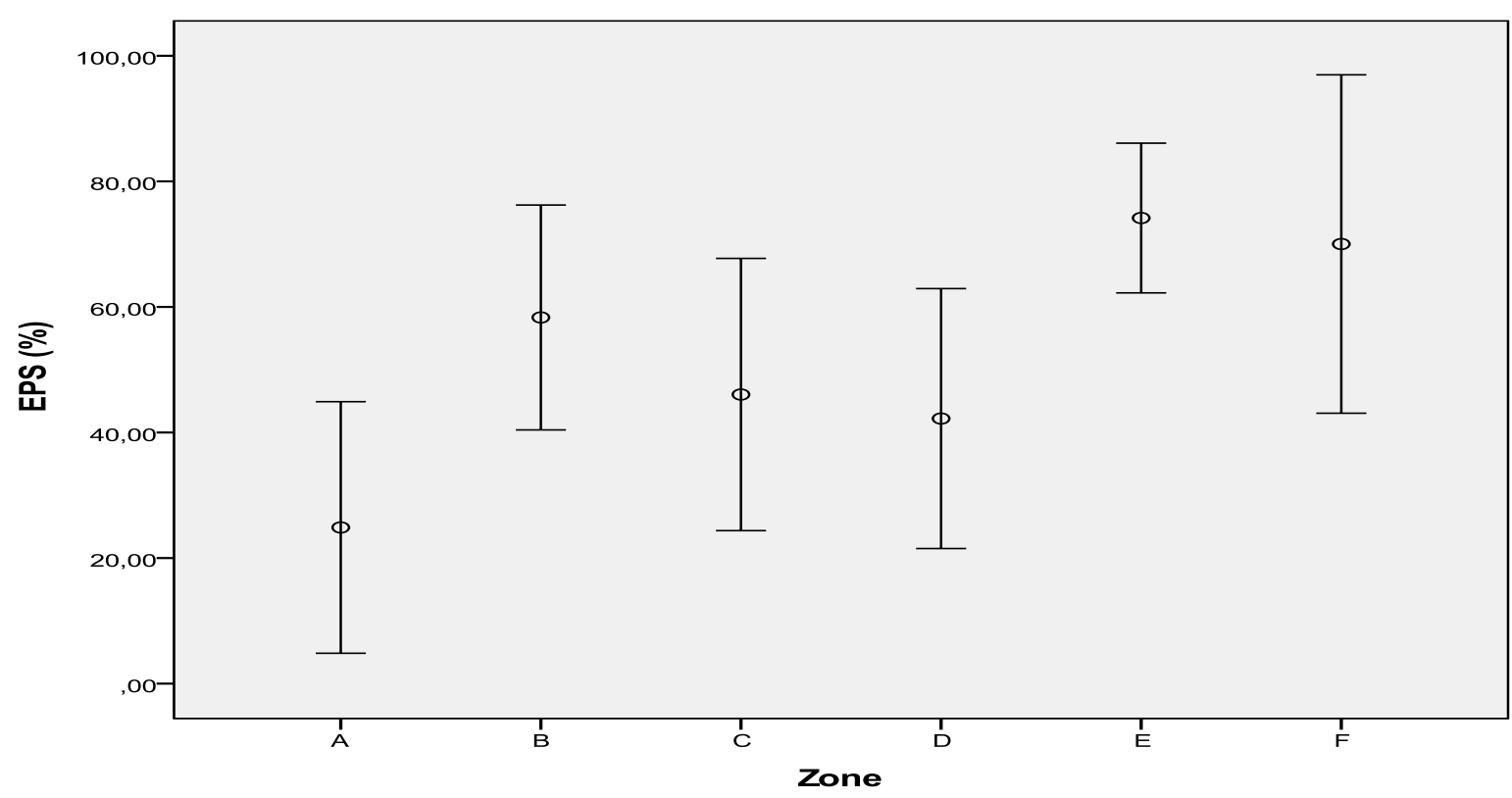

Fig. 5. EPS mean values and their standard deviations for the 6 zones.

\subsection{Water salinity}

Water samples were classified according to the USSLS standards for the classification of irrigation water (Table 2). The results show that $51.5 \%$ of the wells belong to classes $\mathrm{C} 3, \mathrm{C} 4$, and $\mathrm{C} 5$ with waters considered to be highly to extremely saline and therefore. These waters are unsuitable for irrigation since they have a higher potential for soil salinization which could lead to important yield reduction, in particular for for sensitive crops.

Table 2. Distribution of irrigation water's salinity in the SidiYahya region, following the USSLS standards [11].

\begin{tabular}{|l|c|c|c|c|}
\hline Salinity class & Symbol & EC (dS/m) & Number of wells & \% wells \\
\hline Non saline & $\mathrm{C} 1$ & $<0.25$ & 9 & 27.3 \\
\hline Averagely saline & $\mathrm{C} 2$ & $0.25-0.75$ & 7 & 21.2 \\
\hline Highly saline & $\mathrm{C} 3$ & $0.75-2.25$ & 11 & 33.4 \\
\hline Very highly saline & $\mathrm{C} 4$ & $2.25-5$ & 4 & 12.1 \\
\hline Extremely saline & $\mathrm{C} 5$ & $>5$ & 2 & 6.0 \\
\hline
\end{tabular}

\section{Conclusions}

The physical and chemical quality of water and soil of the region of Sidi Yahya (Gharb, Morocco) was evaluated in order to study the impact of intensive agriculture on this quality. The main results of this research work can be summarized as follows. First of all, there was a very low risk of soil salinity in the whole area, whatever the zone. In addition, most of the soils have a basic $\mathrm{pH}$. Moreover, the soils are rich in potassium; therefore fertilizing should be rationally managed in order to avoid any threat to groundwater and surface water (pollution, eutrophication of water bodies, etc.). In contrast, the soils had low phosphorus levels and $60.6 \%$ of them are poor to moderately poor in organic matter, which reflects poor reasoning behind the fertilization of the crops grown.
Regarding groundwater in the downstream zones of the region, more than $51.5 \%$ of the water has a higher potential for soil salinisation and can lead to an important loss of production, in particular for sensitive crops. The main reasons for this high water salinity are the influence of the waters of the Sebou River, the depth of the water and the geological nature of the aquifer.

In conclusion, it is highly recommended to adapt the current crop management and to adopt best management practices with the final aim of maintaining a sustainable productivity of the Sidi Yahya Gharb lands and preserving water and soil resources from degradation. These best management practices can be related to better management of irrigation through the use of water saving techniques, better reasoning of fertilizing (manure and organic fertilizers), etc. 


\section{References}

1. A. Zouahri , H. Dakak, A.Douaik, M. El Khadir , and R. Moussadek. Environmental Monitoring and Assessment Journal. 187(2015) $1-15$.

2. H. Dakak, A. Zouahri, H. Iaaich, R. Moussadek, M. Elkhadir, A.Douaik, B.Soudi , and A.Benmohammadi . Revue des Régions Arides. 33 (2014) 75-79.

3. N.El Khodrani, A. Zouahri, A.Douaik , S.Omrania , H. Iaaich, A.Yahyaoui , M. Fekhaoui. Journal of Materials and Environmental Science.8 (2017) 2339-2346.

4. M. Lahmar ,N. El Khodrani , S. Omrania , H. Dakak, A. Douaik , H. Iaaich , M. El Azzouzi ,M. Mekkaoui , and A. Zouahri . Moroccan Journal of Chemistry. 7(2019) 424-430.

5. S. Omrania , N. El Khodrani, A. Zouahri , A. Douaik , H. Iaaich , M. Lahmar, and S. EL Hajjaji . Materiels Today. 13(2019) 1092-1101

6. N. El Khodrani ,A. Zouahri, A. Arfaoui, H. Iaaich , K. El Oumlouki , A.Yahyaoui , M. Fekhaoui . Journal of Materials and Environmental Science. 7(2016) 2852-2860.

7. M.L. Belghiti, A.Chahlaoui , D. Bengoumi , and R. El Moustaine. Larhyss Journal. 14 (2013) 21-36.

8. K. Tanji. Kenneth, and C.Kielen. Neeltje. (FAO, Agricultural Drainage Water Management in Arid and Semi- arid Areas, ISBN: 9251048398, 2002).

9. Z. Fathallah, K. Elkharrim, R. Fathallah, E.M Hbaiz , C. Hamid, A. Ayyach ,A. Elkhadmaoui, and D. Belghyti. Larhyss Journal. 20 (2014) 57-69.

10. Alice M. Mweetwa, Aswell C. Lubungo, Benson H. Chishala and Mirriam Phiri. Sustainable Agriculture Research; Canadian Center of Science and Education. 5 (2016).
11. U.S.S.L (United State Salinity Laboratory Staff), US Department of Agriculture, Handbook n60, U. S. Gov. Print. (1954).

12. M. Laghrour, R. Moussadek, R. Mrabet, R. Dahan , M. El-Mourid, A. Zouahri, and M. Mekkaoui . Applied and Environmental Soil Science. Article ID 6345765(2016).

13. Hector R. Tévez, and Maria dos Santos Afonso, Bull De la SOCIEDAD GEOLOGICA MEXICANA. 67 (2015) 509-516

14. J. Petard. Les méthodes d'analyses tome 1 Analyses des sols note technique laboratoire commun d'analyse. 5 (1995) 7-25.

15. L. Blanc, D. Chessel, and S.Dolédec, Bull. Fr. Pêche Piscic. 348 (1998) 1 -21.

16. D.B .Duncan . (Multiple rang and multiple F tests, Biometrics.11, 1955)

17. E. Dinon . Gerstmans, African Crop Science Journal. 23 (2015) 101-111.

18. D. Baize . (Guide des analyses en pédologie: choix, expression, présentation, interprétation 2e éd, INRA- Paris. 255, 2000)

19. V.A. Laudicina, A. Novara, V. Barbera, M. Egli, and L. Badalucco. Land Degradation and Development.261(2015) 45-53.

20. K. El oumlouki , R. Moussadek , A. Zouahri, H. Dakak, M. Chati, and M. El amrani. Journal of Materials and Environmental Science. 5 (2014) 2365-2374.

21. A. Day, and K. Ludeke . (Plant Nutrients in Desert Environments. Springer: Berlin, Heidelberg; 35,1993)

22. M. Badraoui , and A. Merzouk . Changes of soil qualities under irrigation: the effect of salt accumulation on water retention by vertisols. In Advanced Course on Farm Water Management Techniques, CIHEAMIAM-B (ed.). Rabat, Morocco, (1994) 145-155. 